\title{
Zika Virus Infection: New Findings Related to Neurological Complications
}

\author{
Diandra Martins e Silva ${ }^{1^{*}}$, Monara Kedma Nunes ${ }^{1}$, Valécia Carvalho ${ }^{1}$, Fernanda Sousa ${ }^{1}$, Cláudio Ventura ${ }^{2}$, Silmar Teixeira ${ }^{1}$ and Victor Hugo Bastos \\ ${ }^{1}$ Brain Mapping and Functionality Laboratory (LAMCEF/UFPI), Federal University of Piauí, Brazil \\ ${ }^{2}$ Department of Biomedicine of Federal University of Piauí, Brazil
}

*Corresponding author: Diandra Caroline Martins e Silva, Universidade Federal do Piaui, Brazil, Tel: + 308-865-8441; E-mail: diandra_martins@yahoo.com.br

Rec date: April 27, 2016; Acc date: May 05, 2016; Pub date: May 10, 2016

Copyright: (C) 2016 Silva DM, et al. This is an open-access article distributed under the terms of the Creative Commons Attribution License, which permits unrestricted use, distribution, and reproduction in any medium, provided the original author and source are credited.

\begin{abstract}
Zika virus infection has attracted attention of the world population, being reported in many countries / territories. The Zika vírus (ZIKV; genus Flavivirus, family Flaviviridae) is a pathogen globally transmitted by emerging mosquitoes (arboviruses) of the genus Aedes spp. Recently in Brazil, the Ministry of Health confirmed the association between ZIKV and microcephaly outbreak in the Northeast, however, is not clear in the studies the pathogenesis of this process, which led us to conduct a review in databases Pubmed, Medline and Lilacs. The literature reports that the clinical manifestations of ZIKV infection are very similar to infections such as dengue and chikungunya, but usually milder and without deaths, however, the absence of specific commercial serological tests for ZIKV, makes infection a clinical challenge in diagnosis. The association of ZIKV with microcephaly is initially related to the first three months of pregnancy and leads to neurological complications that when does not result in death, causes severe functional limitations accompanied by changes in neuropsychomotor development. Because of the increased number of cases of microcephaly associated with ZIKV infection reported in Brazil, further discussions should be carried out.
\end{abstract}

Keywords: Zika virus; Aedes aegypt; Microcephaly; Neurological complications

\section{Short Commentary}

Zika virus infection was reported in several countries/territories, such as Micronesia, Polynesia, Puerto Rico, Chile, Colombia, El Salvador, French Guiana, Guatemala, Honduras, Mexico, Panama, Paraguay, Suriname, Venezuela, and in 2015 the first autochthonous case was published in Brazil [1,2]. The Zika vírus (ZIKV; genus Flavivirus, family Flaviviridae) is a pathogen globally transmitted by emerging mosquitoes (arboviruses) of the genus Aedes spp., including Ae. africanus, Ae. luteocephalus, Ae. hensilli, Ae. aegypti and of growing public health importance [3].

ZIKV is RNA virus positive-sense single-stranded (genome 1,794NT), which is closely related to the Spondweni virus, responsible for Spondweni fever. The virus was identified in Rhesus monkeys during the surveillance of sylvatic yellow fever in a Forest of Uganda in 1947 with the first case in humans in 1952 [4] and was associated for the first time with neurological diseases during the outbreak in French Polynesia after increasing incidence of Guillain-Barré syndrome cases in October 2013 [5].

Clinical manifestations of Zika infection are very similar to infections such as dengue and chikungunya, but usually milder and without deaths [6]. The most commonly reported symptoms in the Yap Island and French Polynesian outbreaks included rash (90-95\%), fever (65-73\%), arthralgia (65-70\%), and non-purulent conjunctivitis (55-63\%) [5]. In Rio de Janeiro, Brazil, the first autochthonous case of infection was a 38 year old man with previous diagnosis of HIV infection and antiretroviral treatment for about 9 years. The symptoms presented include pruritic maculopapular rash, myalgia, asthenia, malaise and conjunctival hyperemia, no fever, arthralgia, retro-orbital pain, lymphadenopathy, headache, sore throat, vertigo and respiratory, uro-genital, neurologic and digestive symptoms [1].

The serological cross-reactivity with other flaviviruses makes difficult the diagnosis of ZIKV infection, which is based on detection of ZIKV RNA in blood through reverse transcriptase polymerase chain reaction specific of ZIKV (RT-PCR) or pan-flavivirus PCR amplification followed by sequencing viral or isolation [7]. Examples of this were the various cases reported in early 2015 in dengue endemic areas in northeastern Brazil. After negative serological and molecular diagnostics for Dengue and Chikungunya, ZIKV was detected by reverse transcriptase polymerase chain reaction from sera of eight patients and result was confirmed by DNA sequencing [8].

The absence of specific commercial serological tests for ZIKV and cross-reactive DENV serology (IgG or IgM) during ZIKV infection available, as well as the similarity of symptoms with other endemic diseases makes ZIKV infection both a clinical and diagnostic challenge [6]. Since the complexity of diagnostic by cross-reactivity and time demands, recent studies with saliva and urine samples indicate a possibility of diagnostic assist routine in the acute phase of infection, with positive results when compared to serum and blood of the same patients $[9,10]$. The lack of notification of the disease and incorrect diagnosis mask the real number of cases and, therefore, its correlation with clinical complications.

Recently in Brazil, the Ministry of Health confirmed the association between ZIKV and microcephaly outbreak in the Northeast since the virus was present in blood samples and newborn tissues that died in the state of Ceará. Until January 2, 2016, it was notified to the Health Surveillance Secretariat of Ministry of Health a total of 174 suspected cases of microcephaly related to infection by Zika virus, identified in 684 municipalities distributed in 21 Federative Units. Among the total cases, 38 suspected deaths were reported [2]. On initial analysis, the risk is associated with the first trimester of pregnancy [11]. 
Microcephaly is a clinical condition defined as a decrease in brain size characterized by head circumference less than $2-4$ standard deviations below the mean for age and gender [12]. Severe microcephaly progresses within 1-2 years after the birth [13], although there are no specific interventions to increase brain growth, secondary microcephaly can be prevented in some conditions, for example, through dietary interventions in infants with phenylketonuria at birth or through surgical release of fibrous sutures in newborns before 1 year age [14].

In a study conducted at the Oswaldo Cruz Foundation, Rio de Janeiro, Brazil, it was investigated two pregnant women in Paraíba diagnosed with fetal microcephaly and symptoms related to infection by Zika virus. Both patients had negative blood results for Zika virus, amniocentesis and quantitative real-time polymerase chain reaction, realized after ultrasound diagnosis of fetal microcephaly. According to the authors occurs the underestimation of cases with the possible acquisition of immunity in endemic areas or because of the rarity of the disease so far. As alterations in the virus genome have been reported, the possibility of a new and more virulent, strain should be considered. Until more cases are diagnosed and histopathological proof is obtained, the possibility of other etiologies cannot be ruled out [15].

The Ministry of Health in Brazil recently presented the Protocol for healthcare in response to the occurrence of microcephaly related to infection by Zika virus, defining the multiprofessional role in assisting to born with microcephaly, besides actions of prevention infection by Zika virus in women of childbearing age and pregnant women. Within the protocol stands out the early stimulation, which aims to increase its skills, addressing the stimuli that interfere with maturation, to favor the motor and cognitive development. The child should be inserted in this program, and the beginning as soon as the baby is clinically stable and extend up to three years old [11].

The individual with microcephaly require special care and permanent. The ideal care for chronic conditions is achieved when health care providers interact with informed patients. When patients are more informed, involved, and empowered, they interact more effectively with health care providers and strive to take actions that will promote healthier outcomes. Therefore, the treatment should consider the possibility of incorporating a patient empowerment model which considers the patient as the most important member of the health team and care managers as key health care collaborators able to enhance and support services to patients provided by physicians in the primary health care system [16].

Because of the increased number of cases of microcephaly associated with ZIKA infection reported in Brazil, further discussions should be carried out. This neurological complications when does not lead to death, causes severe functional limitations accompanied by changes in Neuropsychomotor Development (NPMD), which represents significant costs to public health of the country. These discussions should address the form of transmission, more effective diagnosis, early treatment for neurological disorders, prevention measures and pathogenesis of the disease regarding the presence of microcephaly, and relationship of gestational month with the period of infection. This would minimize the high rates of infection and mortality.
Moreover, it is not clear in the studies the pathogenesis of this process, for example, if there is a relationship of pregnancy month with the period of infection, an important point to formulate an early intervention plan. Also is worrying the emergence of mutants, because they may cause similar or more serious diseases, besides other types of neurological complications not reported in fetuses. In adults, complications resulting from infection by ZIKV may also present new findings.

\section{References}

1. Calvet GA, Filippis AM, Mendonça MC, Sequeira PC, Siqueira AM, et al. (2016) First detection of autochthonous Zika virus transmission in a HIV-infected patient in Rio de Janeiro, Brazil. J Clin Virol 74: 1-3.

2. Ministry of Health, Secretariat of Health Surveillance (2016) Epidemiological Report No 07- Epidemiological week 52/2015 (27/12/2015 a 02/01/2016): Monitoring cases of microcephaly in Brazil.

3. Diagne CT, Diallo D, Faye O, Ba Y, Faye O, et al. (2015) Potential of selected Senegalese Aedes spp. mosquitoes (Diptera: Culicidae) to transmit Zika virus. BMC Infect Dis 15: 492.

4. Campos GS, Bandeira AC, Sardi SI (2015) Zika Virus Outbreak, Bahia, Brazil. Emerg Infect Dis 21: 1885-1886.

5. Buathong R, Hermann L, Thaisomboonsuk B, Rutvisuttinunt W, Klungthong C, et al. (2015) Detection of Zika Virus Infection in Thailand, 2012-2014. Am J Trop Med Hyg 93: 380-383.

6. Zammarchi L, Tappe D, Fortuna C, Remoli ME, Günther S, et al. (2015) Zika virus infection in a traveller returning to Europe from Brazil, March 2015. Euro Surveill 20.

7. Duffy MR, Chen TH, Hancock WT, Powers AM, Kool JL, et al. (2009) Zika virus outbreak on Yap Island, Federated States of Micronesia. N Engl J Med 360: 2536-2543.

8. Zanluca C, Melo VC, Mosimann AL, Santos GI, Santos CN, et al. (2015) First report of autochthonous transmission of Zika virus in Brazil. Mem Inst Oswaldo Cruz 110: 569-572.

9. Gourinat AC, O'Connor O, Calvez E, Goarant C, Dupont-Rouzeyrol M (2015) Detection of Zika virus in urine. Emerg Infect Dis 21: 84-86.

10. Musso D, Roche C, Nhan TX, Robin E, Teissier A, et al. (2015) Detection of Zika virus in saliva. J Clin Virol 68: 53-55.

11. Brazil (2015) Health care protocol and response to the occurrence of microcephaly related to infection by Zika virus. Brasília: Ministry of Health.

12. Narayanan M, Ramsey K, Grebe T, Schrauwen I, Szelinger S et al. (2015) Case Report: Compound heterozygous nonsense mutations in TRMT10A are associated with microcephaly, delayed development, and periventricular white matter hyperintensities. F1000 Research 4: 912.

13. Battal B, Ince S, Akgun V, Kocaoglu M, Ozcan E, et al. (2015) Malformations of cortical development: 3T magnetic resonance imaging features. World J Radiol 7: 329-335.

14. Harris SR (2015) Measuring head circumference: Update on infant microcephaly. Can Fam Physician 61: 680-684.

15. Oliveira Melo AS, Malinger G, Ximenes R, Szejnfeld PO, Alves Sampaio $S$, et al. (2016) Zika virus intrauterine infection causes fetal brain abnormality and microcephaly: tip of the iceberg?. Ultrasound Obstet Gynecol 47: 6-7.

16. Ciccone MM, Aquilino A, Cortese F, Scicchitano F, Sassara M, et al. (2010) Feasibility and effectiveness of a disease and care management model in the primary health care system for patients with heart failure and diabetes (Project Leonardo). Vascular Health and Risk Management 6: 297-305. 